\title{
Increasing the Internal Quality in College Schools via Democratic Dimensioning of Parent-Teacher Communication
}

\author{
PhD Candidate Bledina Bushi
}

\author{
Aleksander Moisiu University, Faculty of Education \\ Durres, Albania \\ E-mail: ccf_bbushi@yahoo.com
}

\section{Doi:10.5901/jesr.2013.v3n7p339}

\begin{abstract}
Ensuring internal education quality is considered as one of the priority issues under the Albanian political agenda for integration. In college, the development of effective parent-teacher partnership is vital because optimises both teaching and learning. The level of parent's involvement depends significantly on the formats, methodology and philosophy of parent-teacher communication. An empirical survey undertaken in 2012 studied the reality family-school communication in Durres college schools. It is oriented towards parents' perspective for explaining why parents are withdrawn. The paper explores the findings, confronts them with the empirical data of the research literature. From the analysis and arguments are generated recommendations on potential forms of treatment and management with regard to parent communication in college schools. The gathered data indicated that the parent-teacher communication reality is far from being considered consistent and its efficiency is partial. The communication is seen with darker lens from parents of female students, parents with children in the margin grades of college, mothers, parents with college education, the unemployed and those who live in Durres from over a decade. The paper proposes a dimensioning of parent-teacher communication, which should be reviewed periodically. Despite backgrounds, positions and the limited resources can be shaped an interaction model built on strengths.
\end{abstract}

Keywords: democratic dimensioning of parent-teacher communication, college school, quality education.

\section{Introduction}

Albania has experienced a major transformation since the early 1990s, and the expansion of high education is one of the most substantial changes affecting the education system (UNICEF 2007). The law no 7952 date 21.06.1995 "For the pre-university education system" considers that education in Albania is realised in conformity to the sanctioned principles of the law in power and in conformity to the international treaties and agreements ratified by the Albanian Republic (Article 1). Whereas the "Normative dispositions for the public schools" (1996) legitimate the importance of cooperation of educational institutions with the parents (article 54/1), and details the involvement spectrum. Ensuring comprehensive high-quality teaching and learning are considered as priority issues under the Albanian political agenda for integration.

The European report on education indicators (2000) identified 16 quality indicators which cover four broad areas: a) attainment levels (mathematics, reading, science, information and communication technologies, foreign languages, learning to learn, civics); b) educational success and transition (drop out, completion of upper-secondary education, participation in tertiary education); c) monitoring of school education (evaluation and steering of school education, parental participation); d) educational resources and structures (education and training of teachers, participation in preprimary education, number of students per computer, educational expenditure per student). OECD in 2005 summarized results from a survey undertaken in USA and Europe and created three main categories of school factors important in educational effectiveness: a) resource input variables (pupil-teacher ratio, teacher training, teacher experience and teachers' salaries), b) school organisational factors (achievement pressure for basic subjects, educational leadership, monitoring/evaluation, cooperation/consensus, parental involvement, staff development, high expectations and orderly climate); c) instructional conditions (opportunity to learn, time on task/homework, monitoring at classroom level, aspects of structured teaching, differentiation/adaptive instruction). Considering those approaches, parental involvement is a challenging piece that helps in completing the mosaic of quality in schools.

Epstein, a prominent researcher in the field of parent involvement designed a framework of six parental involvement forms which comprises communicating, parenting, learning at home, decision-making, volunteering and collaborating with the community (Epstein, J. 1995). The development of effective parent-teacher communication is vital 
in the high school context because optimises both teaching and learning. A few researches targeting Albania reveal that schools collaborate with the parents, but the partnership is crushed (Pop, D. 2009; Musai, B. 2009; Boce, E. 2010; Bushi, B. 2011). Communication can be defined as the intentional or unintentional activity of transmitting information by verbal and non-verbal means of communication. An effective parent-teacher communication serves to the different purposes for which it was planned or designed, and ensures that messages aren't distorted during the communication process. Since presently a little is known about how effectively communicate parents and teachers in the pre university education reality in Albania, the empirical researches are a must. They can indicate how can be developed a democratic dimension of communication (which builds active and open schools, cultivates cooperation with parents and community as well as activates students).

In a former study in 2012 are studied three college schools from Durres city. The study was carried out with the permission, the voluntary and well-informed cooperation of the local education institutions. The survey primary goal was to explore parents insights on parent-school communication. In each of the involved schools were randomly selected two parallels. Within grade parallels were randomly selected equal numbers of male and female students, the parents of which were invited to complete a questioner. About 180 questionnaires were distributed, but those who weren't returned within a week, were excluded from the statistical analysis of the empirical data. In addition were excluded even the questionnaires that had unanswered items. Those decreased by $18,9 \%$ the initial sample. Most of responses were given on a 5-point scale, ranging from definitely not agree (indicates a strong negative perspective) to definitely agree (indicates a strong positive perspective). In this regard, from the responses were generally considered the negative perspectives. The questionnaire ensured data about participants' behaviours, attitudes and personal background, while guaranteed the privacy.

Completed the questionnaire $62,3 \%$ mothers and $37,7 \%$ fathers. The reply was higher from the parents of female students $(58,9 \%)$ comparing to the male peers $(41,1 \%)$. Considering students' grade, the responses reached their peak in the XI grade for mothers and in the XII grade for fathers, while the lowest value is meet respectively in the XII and XI grade. Almost all respondents were mainstream Albanian, while a marginal of $0,7 \%$ belonged to the Egyptian community. About $95,9 \%$ reported to be married, but were limited cases of divorced $(1,4 \%)$ and widow $(2,7 \%)$ parents. In terms of education level, most of participants had finished the college $(63,7 \%)$ and university $(29,5 \%)$ while only $6,8 \%$ the secondary school. When asked for their employment status $28,1 \%$ of parents were unemployed, $70,5 \%$ employed and only 1,4\% retired. The majority of respondents are adapted in Durres city, as they report to live in this area from over a decade (specifically $35,6 \%$ are living from eleven to twenty years and $41,8 \%$ from more than twenty years and as such their children can be considered "native" in Durres). Almost 6,2\% live in Durres from less than five years, whereas 16,4\% report that are living in this city from six to ten years.

Figure 1.Years of living in Durres city versus parents` gender belonging

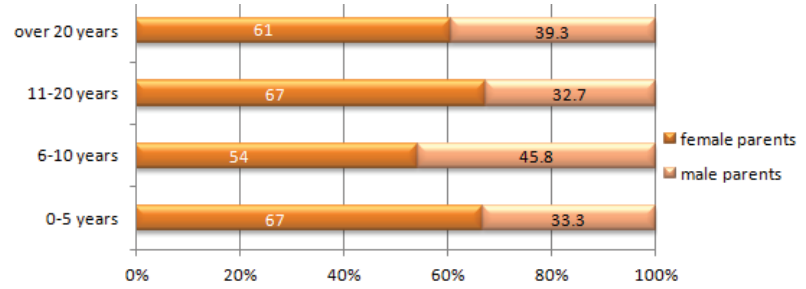

The data coming from the above mentioned demographic variables show that respondents differed considerably in gender, education level, employment status, and length of self-reported time living in Durres city, while were more homogenous in sense of ethnicity and civil status. That's why when we will assess the parent teacher communication reality we will pay special focus to variables such as child gender and grade, relationship with the child, education level, employment status, and length of time living in Durres.

\section{Results}

\subsection{Frequency and initiation of parent-teacher communication}

The transition from secondary to the college school requires frequent parent-teacher communication for finding solutions 
or preventing student's problems, but the figures from the college schools under study reveal that according to parent perceptions the reality is far from ensuring consistent parent-teacher communication during the school year. With the increase of child's grade, parents report to communicate more often with teachers. It is concerning that almost half of the parents which communicate with teachers maximally once a year, have their child in the first year of college. Around one in every three parents who communicate with teachers two to five times per school year has the child in the second year of college. The frequency is similar even in the case of respondents which communicate with teachers over six times per school year, but have a child in the third year of college. Even though parents of female students report to communicate more often with teachers, wasn't found significant distinction between the rates of female and male parents for each of the above mentioned frequencies of communication. The respondents who communicate up to one time per school year with teachers, are dominated by parents with secondary education (60\%), compared to those with college $(30,2 \%)$ and university education $(9,8 \%)$. The variances between different education levels are less important if parents communicate two to five times per year (29,4\% secondary, $35,1 \%$ college and $35,5 \%$ university), than in the case they communicate over six times (30,4\%secondary, 50,6\% college and 19\%university education). The unemployed parents advance 1,5 times the rate of the employed peers which communicate with the teacher up to one time per school year. Whereas alike rates of employed and unemployed parents (47,8\% versus $52,2 \%)$ affirm that have contacted teachers two to five times during the school year. About half of parents which declare that communicate with teachers over six times during the school year are unemployed, 48,5\% are employed and only 4,1\% retired. As Figure 2 shows, the rate of parents who report that are contacting teachers up to one time per school year is decreasing with the increase of years of living in Durres city, while is increasing in the case of the parents that report that contact the school two to five times, and over six times per school year.

Figure 2. Frequency of parent-teacher communication versus years of living in Durres

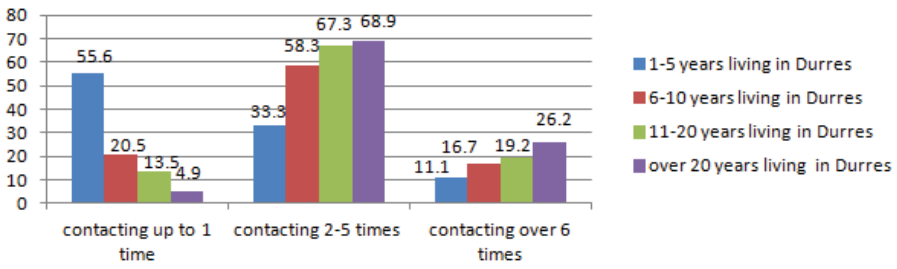

When asked which had generally initiated the communication with the school, only $12,3 \%$ of respondents $(17,6 \%$ female and $3,6 \%$ male) reported that established two-way channels for communication (home to school and school to home). About $45,9 \%$ of parents attributed to teachers the first step (42,9\% female and $50,9 \%$ male) while $41,8 \%$ said that have initiated the communication themselves (39,6\% female and $45,5 \%$ male). As Figure 3 shows parents with children in the lower grades of college report higher rates of teachers as initiator. Whereas with the increase of child grade the situation is reversed and parents are more based on their individual or joint parent-teacher initiative.

Figure 3. The initiative for starting parent-teacher communication versus childs` grade

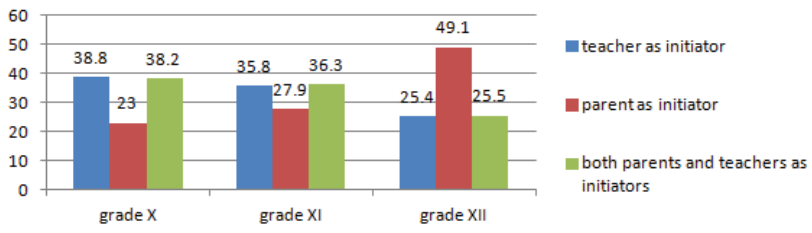

Is higher the share of the unemployed parents that perceived the communication connected with tutors' initiative $(63,4 \%)$, comparing to the share that recognized mutual parent and teacher initiatives $(36,6 \%)$. From the employed respondents $45,4 \%$ reported to be based on their enterprise for interacting with the teacher, $42,2 \%$ were influenced by tutors while $12,4 \%$ relate it to the impulse provided from both themselves and tutors. The parents with college and university education result to be more initiative, comparing to their peers with secondary level. According to the answers provided, with the increase of the years a parent is living in Durres increases even parents' confidence to initiate on their 
own the communication with the tutor.

To capture some reasons that stay in the grounds of the infrequent parent-teacher communication and the low parent based initiative for starting interaction, we concentrated on parents' opinions with regard to: a) the infrastructure; b) the feeling of being welcomed and treated equally by the teacher; c) the update and communication openness; d) the consideration of parent's engagements, views and prospects.

\subsection{Perceptions on the infrastructure}

When studying the adequacy of the infrastructure, were observed complex scores in parents' responses. Within those who definitely disagree that there are adequate infrastructural conditions that stimulate the parent teacher communication the rate of mothers overcomes 4,5 times the fathers'. Even in the case of those who disagree in this respect, mothers dominate over fathers to a reduced extent ( 2,5 times). The share of parents with sons who disagrees and categorically disagrees that are adequate infrastructural conditions is smaller comparing to parents with daughters. The findings reveal that are evidenced small differences between the rates of unemployed, employed and retired parents who strongly disagree (respectively $27,3 \%, 72,7 \%$ and $0 \%$ ) or disagree (respectively $30,8 \%, 64,1 \%$ and $5,1 \%$ ). Considering the variances of the responses with regard to respondents education level, the values aren't concentrated in the extreme values, but instead are either spread in the case of those who absolutely disagree $(9,1 \%$ secondary, $54,5 \%$ college and $36,4 \%$ university education) or disagree $(12,8 \%$ secondary, $59 \%$ college and $28,2 \%$ university education) on the infrastructure appropriateness. It is also important to mention that those who live in Durres from over a decade report higher unconditional disagreement and disagreement rates (respectively $72,8 \%$ and $79,5 \%$ ) compared to their peers living from up to a decade (respectively $27,3 \%$ and $20,5 \%$ ).

\subsection{Perceptions on being welcomed and treated equally by teachers}

Overall we observed variations with regard to parent perceptions on being welcomed and treated equally by teachers. Is striking that all those who don't feel absolutely welcomed by teachers are mothers, employed, have daughters, children in the second year of college or college education, and live in Durres city from over a decade. Of those who confirm that don't feel welcomed the share is 1,5 times higher in the case of parents with sons versus with daughters, in contrast is 1,5 times minor the share of parents with children in the first versus the third year of college. We evidenced differences between the rates of mothers (60\%) and fathers (40\%) who negate that teachers welcome them. The rate of those who disagree that feel welcomed is four times advanced in the case of parents with college versus those with university education. From those who said that categorically don't feel welcomed are all employed parents and parents which live in Durres from over a decade. The rates of those who perceive that aren't welcomed by teachers are identical with regard to parent's employment (60\% unemployed versus $40 \%$ employed) and years of living in Durres city (60\% live from up to a decade versus $40 \%$ live from over a decade).

For encouraging mutual communication is important to discover if teachers communicate with all parents despite their background. The findings reveal that despite child's grade level disagree that teachers communicate with all parent very similar rates of parents, while is twice higher the share of parents with college education $(66,7 \%)$ compared to their peers with university education (33,3\%). It is also important to note that from those who report that teachers don't communicate with all parents, the rate of respondents increases with the increase of child's grade $(16,7 \%$ in the first, $38,9 \%$ in the second and $44,4 \%$ in the third year of college), while shifts with the increase of parent education (16,7\% with secondary, $61,1 \%$ with college and $22,2 \%$ with university). An overwhelming majority of parents with sons feel more experienced and confident to absolutely disagree that teachers communicate with all parents, but when it comes to disagree dominate parents with daughters. The employed parents report absolute disagreement rates which are twice higher, than those of the unemployed peers. About $66,7 \%$ of the unemployed, $27,8 \%$ of the unemployed and $5,6 \%$ of the retired peers told that teachers don't communicate with all parents. Is inferior the rate of respondents which strongly negate to have created equal communication in the case they live in Durres city from up to a decade $(33,3 \%)$, comparing to their peers who live from over decade $(66,6 \%)$, while the values are more extreme in the case when they disagree $(16,7 \%$ for those who live from up to a decade and $83,9 \%$ for those who live from over decade in Durres).

\subsection{Perceptions on the updated and communication openness}

The parents who deny that teachers have informed them on the progress and behaviour of their child are divided in two 
equal shares between the respondents with children in the first and third year of college. All the parents with the child in the first year of college agree that the info provided from the teachers cannot be understood from them is unbelievable and unclear. Less parents confirm this in upper classes $(66,7 \%, 40 \%$ and $50 \%$ in the second year, while $33,3 \%, 60 \%$ and $50 \%$ in the third year of college).

No significant variance is found between the rates of mothers and fathers which intensely negate to openly communicate with the teacher, while are extreme for those who refute to have communicated openly (respectively $81,8 \%$ for female and $18,2 \%$ for male parents). Notwithstanding the disagreement degree, the proportions of parents with female students overcome those of male peers. From respondents who affirm that don't speak openly with teachers, $45,5 \%$ have a child in the third year of college, whereas the remaining is divided in two equal shares $(27,3 \%$ each)between those with children following the first and second year of college. When it comes to parents who perceive that teachers are categorically reserved in communication, the share of parents with children in the third year of college is three times higher versus those with children in the first year. Despite the disagreement degree, the reported proportions are higher for the parents with college education, followed respectively by their peers with university and secondary graduation. From those who absolutely negate that communicate openly with teachers are divided in two equal shares between the employed and unemployed respondents. While the frequency of those who are reserved in communication is much higher in the case of those who are employed $(81,8 \%)$ than the unemployed peers $(18,2 \%)$. Is surprising that over $75 \%$ of the parents which report that have absolutely failed in establishing open communication with the teacher are living in Durres from over a decade. The rate is even higher in the case of those who have failed to build an open communication with teachers $(81,9 \%)$.

\subsection{Perceptions on the consideration of parent's engagements, views and prospects}

The composite score indicates that from those who strongly disagree that teachers consider their engagements in the family or work about $50 \%$ are respondents of children in third year, $37,5 \%$ in the first and $12,5 \%$ in the second year of college. We observed that the rate of those who report disagreement on this issue, increases with the increase of child's grade $(12,5 \%$ are parents of children in the second year of college $40 \%$ in the second and $44 \%$ in third year). The highest rates of those who strongly negate or negate that teachers consider their schedules were found in the case of girls' parents (respectively $62,5 \%$ and $72 \%$ ). According to the responses, mothers report higher rates of negative perspectives (75\% and 68\%) paralleling to fathers (25\% and $32 \%)$. With regard to education the rates are of parents who report that definitely disagree that their agendas are considered, is higher in the case of parents which have college education $(62,5 \%)$ comparing to their peers with university $(25 \%)$ and secondary $(12,5 \%)$ education. In the case of those who disagree on this issue, there are no differences between the parents with college and university (44\% each), while their peers with secondary education don't overcome the value of $12 \%$. There are shifts in the rate of parents who perceive that the teachers don't consider their schedules (36\% unemployed, 60 employed and $4 \%$ retired) and those who definitively don't consider (62\% unemployed and 37,5\% employed parents). Teachers are considered absolutely insensitive towards parents schedules for $37,5 \%$ of the respondents which live in Durres from up to a decade and $62,5 \%$ of those who live in this city from over decade. Those figures are more balanced compared to their peers who simply disagree on this topic (12\% and $88 \%)$.

Is twice higher the rate of parents with secondary education who categorically disagree teachers consider the views and prospects of parents $(66,7 \%)$ compared to those with university education $(33,3 \%)$. The rate of parents with secondary education who don't agree that teachers consider their thoughts and expectations is $14,3 \%$, this is twice minor than the rate reported by their the peers with university $(28,6 \%)$ and for times lower than the share of those with college $(66,7 \%)$.

Mothers declare higher rates of categorical disagreement and disagreement (respectively $73,3 \%$ and $68,6 \%$ ) than fathers $(26,7 \%$ and $31,4 \%)$. Considering the variances of the responses with regard to respondents employment, the values are less spread in the case of those who absolutely reject (73,3\% employed and $26,7 \%$ unemployed) than in the case of those who reject (60\% employed and 36\% unemployed) that teachers mirror parents thoughts and expectations. Notwithstanding the disagreement degree, the parents with daughters seem to be the most critical with regard to consideration of parent's thoughts and expectations. From those who express that absolutely disagree that teachers reflect parents thoughts and expectations the reported rates are similar for parents with children in first and second year of college ( $40 \%$ each) and is split in the case of those with children in the third year (20\%). Similar results are obtained even in the case of parents who disagree that teachers have valued their thoughts and expectations (20\% of the parents with children in the first, $40 \%$ in the second and $40 \%$ third year of college). Three to four participants who 
live in Durres from over decade perceive that teachers absolutely don't consider parents thoughts and expectations during the communication, while about five to six participants in the study who live from over a decade in this city disagrees that teachers consider them.

\section{Discussion}

Traditionally teachers are conceived as responsible for teaching academic skills (in school setting), while parents for educating children with moral principles (in the home). This mentality can stimulate a low interaction of parents with the educational system in general and teachers in particular especially in the first years of college. In specific context settings the remoteness from school and the inadequate school environment conditions and can hamper the mutual communication between parents and teachers. Family and work responsibilities or constraints, and perceived gender roles, influence on parents 'initiative to communicate with a teacher. Especially if are affected by migration, a decrease in the income, a divorce or death in the family parents can be more distant. Even though nowadays the Albanian legislation demands frequent info sharing, both parents and teacher's values can generate confusion. The restricted resources, interlinked with the low capacities can influence on the frequency and communication modes used. Especially parents with low education can face difficulties for understanding teachers messages, or can nurture the belief that what they communicate is irrelevant, unappreciated and will be opinionated. The difficult personality types and physiological conditions can also impede creation of continuous and effective interactions. The above is reflected in previous studies including: Duncan, 1992; Lewis, 1992; Wanat, 1992; LaBahn, J. 1995; Dixon, 1992; Brink. C, 1993; Vandergrift. J, 1992; Brito, J. 1994; Fryer, L., 2011. Gollnick, D..M 2002; Hislop.H., 2010; Keith, T 1998; Kratochwill, T. R. 2004; Levy, J. 1997; McNergney, R.F 2001; Twitty, J.R. 2002; Bushi, B. 2011 etc.

The findings presented in this paper, are locality and time sensitive and a modest approach to the issue of parentteacher communication. It is certainly necessary to attempt to use systematic research and more comprehensive samples in both urban and rural areas to ensure representativeness of results. Notwithstanding the limitations it is our hope that this work might serve as a small step on the long road towards building quality education via dimensioning the communication in a democratic way. We hope that the findings of this research will act as a drive for reflection on parentteacher communication practices for optimising adolescent students learning and development.

\section{Recommendations}

The parent-teacher dimensioning of communication should be seen as a holistic development approach, not as an absurd domino game which participants are forced to play in specific moments of the education. In this regard, the democratization can ensure adequate plasticity for interconnection. The improvement of policies and procedures should go along with the provision of adequate financial resources and time-devotion from main actors. With all parents despite the background should be established on time, constructive and regular two-way communication (during and after school). Considering parents' engagements and resources, in addition to traditional forms of communication (such as parents' conferences, individual meetings and information letters), can be considered the feasibility for use of e-mails, phone lines, student journals, school manuals etc. The personal growth, peer support and creation of friendly environments can generate strategic impulses. The communication practices should be creatively revised at least every school year, and adapted based on parents and teachers inputs.

\section{References}

Boce, E., (2010). Përfshirja e Prindërve në Jetën e Shkollës në Shqipëri. Fondacioni Soros.

Brink, C., (1993). Teach the parent; reach the child. Vocational Education Journal.

Brito, J. \& Waller, H. (1994).Partnership at a price? R. Merttens, D. Mayers, Brown, A., Vass, J, Ruling the Margins: Problematizing Parental Involvement. London: Institute of Education, University of London.

Central and Eastern Europe and the Commonwealth of Independent States

Bushi. B,, (2011) Psycho social factors that strengthen the relationship between teachers and parents. Conference proceedings International Conference on Developmental problems of childhood and adolescence in transitional societies. 2-3 December 2011 Durres Albania

Dixon , A. Why multicultural education is more important in higher education now than ever. A global perspective. An online paper available at. http://www.google.com/search?sourceid=navclient\&ie=UTF8\&rlz=1T4SKPT_enAL437AL442\&q=Dixon+\%2c + A. + Why+multicultural+education+is+more+important

Dixon, A.P, (1992, April), Parents: Full partners in the decision-making process. NASSP Bulletin. 
Duncan, C., (1992). Parental support in schools and the changing family structure. NASSP Bulletin.

Epstein, J. L. (1995). School-family-community partnerships: caring for children we share. Phi Delta Kappan.

European Commission, Directorate-general for education and culture.(2000). European report on the quality of education, sixteen quality indicators. European Communities (2001).

Fryer, L., (2011). A coherent approach to high school improvement: A district and school self-Assessment Tool, National Hight Scool Center.

Georgiou, S. Parental involvement: Beyond demographics. An online paper available at http://www.google.com/search?sourceid =navclient\&ie=UTF8\&rlz=1T4SKPT enAL437AL442\&q=brito+Partnership+at+a+price\%3f

Gollnick, D.M., \& Chinn, P.C. (2002). Multicultural education in a pluralistic society (6th ed.). Upper Saddle River, NJ: Pearson Education Inc.

Hislop.H., (2010). Parents, school evaluation and school improvement. National Parents' Council, Conference.

Keith, T., Keith, P. B., Quirk, K. J., Sperduto, J., Santillo, S. \& Killings, S. (1998). Longitudinal effects of parent involvement on high school grades: Similarities and differences across gender and ethnic groups. Journal of School Psychology.

Kratochwill, T. R., (2004) Families and Schools Together. Journal of School Psychology.

LaBahn, J. (1995). Education and parental involvement in secondary schools: Problems, solutions, and effects.

Albanian law on the pre-university education no. 7952, dated 06.21.1995 http://www.seeeducoop.net/education_in /pdf/law_on_pre_univ_educ_syst-alb-enl-t04.pdf

Levy, J. (1997). The VENN view of diversity: Understanding differences through similarities. Available at http://www.iteachnet.com IApril97/NennDiversity.htm

Lewis, J., (1992). Death and divorce - helping students cope in single-parent families. NASSP Bulletin.

McNergney, R.F., \& Hebert, J.M. (2001). Foundations of education: The challenge of professional practice. Boston: Allyn and Bacon.

Musai, B., (2009). Advancing Participation and Representation of Ethnic Minority in Education Albania. Normative dispositions for the public schools in Albania dated 1996.

OECD 2005, School Factors Related to Quality and Equity OECD results from Pisa 2000.

Pop. D., (2009). School governance and social inclusion, involvement of parents- South east Europe.

The Journal of education and research (2012). VOL2. No 5. The impact of parental partnership in school evaluation as a base for diagnosis and improvement - An experience from Durres high schools contexts. Mediterranean Center for Social research (Italy on March 2012).

Twitty, J.R., Mesaric, T.C. (2002).The importance of welcoming diversity on college campuses. Conference and Program Proceedings of the National Conference on Multicultural Affairs in Higher Education, October 20-23, 2002, San Antonio, Texas.

UNICEF.(2000). Education for Some More than Others?, Geneva: UNICEF Regional Office for

UNICEF.(2000). Defining quality in education. A paper presented by at the meeting of The International Working Group on Education Florence (Italy on June 2000).

Vandergrift, J., (1992). Rethinking parent involvement. Educational Leadership.

Wanat, C., (1992). Meeting the needs of single-parent children: School and parent views differ. NASSP Bulletin. 